\title{
Los cuatro mantras de los posdictadores argentinos en la primavera democrática ${ }^{1}$
}

\section{Four mantras of former Juntas members in Argentine democratic transition}

Diego Galante ${ }^{2}$

\section{Resumen}

El artículo analiza las representaciones sobre la violencia represiva en los discursos de los excomandantes de las Juntas Militares argentinas (1976-1983) puestas en escena en sus presentaciones en el Juicio a las Juntas durante la transición a la democracia (1985). A partir de un tratamiento cualitativo, se enfoca en el orden simbólico de esos discursos y se los organiza temáticamente a partir de cuatro ejes estructurales y transversales: la idea de la «guerra antisubversiva», las relaciones atribuidas a la «obediencia», su valoración sobre el proceso penal, y el rol asignado a las Juntas en la conducción represiva.

Palabras clave: Juntas Militares; Juicio a las Juntas; violencia represiva, transición política, guerra antisubversiva.

\begin{abstract}
The author analyzes the representations on repressive violence in the speeches of the members of the Argentine Military Juntas (1976-1983) that was made at the Military Juntas Trial (1985). The paper, focused on a qualitative approach presents four thematic objects as the main themes at that speeches: the «counter-subversive war», the idea of «obedience», their perceptions about the trial in course, and the role of the Juntas.
\end{abstract}

Keywords: Military Juntas; Military Juntas Trial; repressive violence; political transition, counter-subversive war.

\section{Introducción ${ }^{3}$}

A pesar de haberse concebido, en alguna medida, como un régimen empeñado en borrar sus huellas, distintos avances se han realizado

\footnotetext{
1 Trabajo recibido el 20/05/2020. Aceptado el 30/06/2020.

${ }^{2}$ Universidad de Buenos Aires. Contacto: jdjgalante@gmail.com

${ }^{3} \mathrm{El}$ artículo presenta resultados de la investigación desarrollada en el marco del Proyecto PICT 2013-0299, «Las declaraciones públicas de represores: narrativas y conflictos en la memoria social sobre el terrorismo de estado en la Argentina», dirigido por Claudia Feld, FONCyT-CONICET, Argentina.
} 
para la comprensión de las dimensiones sustantivas del régimen de desaparición de personas instaurado en Argentina en marzo de 1976. Además de la información desarrollada en la órbita de organismos de la sociedad civil, iniciativas de gobierno, y el campo judicial, la violencia represiva ha sido objeto de distintos trabajos académicos. Entre otros, trabajos como los de Cheresky (1998), Novaro y Palermo (2003), Quiroga (2004), y Canelo (2008, 2016), por una parte, han permitido conocer el entramado político del proyecto represivo en su entroncamiento de una faz pública y una clandestina, sus fricciones internas, y sus relaciones complejas con el sistema político argentino. Otras investigaciones recientes se han abocado a la reconstrucción de las prácticas represivas, indagando en sus variables constitutivas, sus relaciones de continuidaddiscontinuidad con la violencia de Estado, o bien explorando sus aspectos menos familiares (entre ellas, Franco, 2012; Bacci et al., 2012; Águila et al., 2016; D’Antonio, 2018). Finalmente, una gama más acotada de trabajos ha explorado las dimensiones simbólicas de las prácticas represivas en sus agentes y sus memorias sobre la represión (Robben 1995, 1999; Herschberg y Agüero, 2005; Badaró, 2009; Canelo, 2010; Feld, 2001, 2016; Salvi, 2012, 2015, 2016).

El presente trabajo se inscribe en esa última serie de indagaciones y tiene específicamente por objeto analizar las declaraciones de los excomandantes de las Juntas Militares durante el «Juicio a las Juntas», cuyas audiencias se condujeron en $1985 .{ }^{4}$ Se asume como hipótesis que el análisis de las intervenciones de los posdictadores durante las audiencias de 1985 permite echar luz sobre el proceso de conformación de sus representaciones y memorias sobre el terrorismo de estado, interpeladas en ese momento bajo el nuevo orden democrático y en un contexto de alta exposición pública, a partir de las mediaciones producidas entre el marco judicial (en el que procuraban impunidad) y un discurso político (la defensa de la «guerra antisubversiva»). ${ }^{5}$ Se considera también que el

\footnotetext{
${ }^{4}$ El juicio oral y público tuvo por finalidad evaluar la responsabilidad penal de los excomandantes de las tres primeras conformaciones (1976-1982) de la Junta Militar por los crímenes en ejercicio del poder. La sentencia de la Cámara Federal del 9 de diciembre de 1985 condenó a Videla y Massera a cadena perpetua, a Viola a 17 anLos de prisioìn, Lambruschini recibiò̀ ocho anĐos de condena y Agosti cuatro anbos y medio. Galtieri, Graffigna, Anaya y Lami Dozo fueron absueltos.

${ }^{5}$ En el contexto histórico de la transición, ha sido identificada la intransigencia de las fuerzas armadas para la revisión judicial del pasado como el conflicto político más candente del período (Acuña y Smulovitz, 1995), y en cuanto a las representaciones dominantes en la
} 
análisis de esas voces posee un interés particular en el contexto transicional, ya que el juzgamiento de esos represores se colocó en el centro (político, judicial y simbólico) del proyecto de justicia ideado por el gobierno de Alfonsín (Galante, 2017).

Metodológicamente, el trabajo se apoya en un tratamiento cualitativo de esos discursos y su organización temática (Glaser y Strauss, 1999). Las fuentes involucraron las presentaciones ante la Cámara Federal de los doce miembros de las Juntas Militares como su materia central (los testimonios de Nicolaides, Franco y Hughes - no imputados en el evento penal- de abril de 1985 y los descargos de los nueve acusados, entre octubre y diciembre de ese año) e incorporaron otras piezas discursivas, tales como las previas declaraciones ante el Consejo Supremo de las Fuerzas Armadas en 1984, las intervenciones de los abogados defensores, documentos de la Junta Militar, otros testimonios de militares y civiles durante el curso penal, o las escenas de la requisitoria de penas y la lectura del fallo del tribunal. ${ }^{6}$

Las presentaciones de los miembros de las Juntas variaron en sus características. Por un lado, se apreció un desfasaje entre los testimonios de la última Junta Militar (en la primera semana de audiencias) y los de los nueve acusados (en el último capítulo de las audiencias, previo al receso que antecedió a la lectura de la sentencia de la Cámara Federal). Por otro lado, también variaron en su extensión. La más breve de ellas agrupó una docena de palabras y las más extensas abarcaron media hora de duración. La presentación de Videla tuvo una característica especial,

cosmogonía militar, Canelo (2008) ha analizado la formación del «consenso antisubversivo» durante la dictadura (basado en un diagnóstico compartido sobre la naturaleza del enemigo, la validez de los métodos para su erradicación, y la convicción de la legitimidad y necesidad de la «masacre represiva»). Salvi (2015) ha rastreado la primacía de la figura de la «guerra antisubversiva» (y su reivindicación como contracara de los «excesos»-figura que ocupaba el centro de las denuncias en la opinión pública-) en las alocuciones públicas de los militares en los primeros años de la transición.

${ }^{6}$ Las fuentes primarias adoptadas incluyen los registros filmográficos de la Cámara Federal, las transcripciones taquigráficas de las audiencias, y material de prensa del período. El acervo filmográfico se encuentra disponible para consulta pública en el Archivo Nacional de la Memoria y en la sede central de Memoria Abierta. Para las citas, se las adoptan transcripciones taquigráficas de los descargos publicadas en El Diario del Juicio (núms. 22 a 31, del 22/ 10 al 24/12/1985). Para el caso de Videla, quién se negó a declarar ante la Cámara Federal, se utilizan las notas de «Solicitud para no comparecer a la audiencia de acusación» cursada en agosto de 1985 (en El Diario del Juicio, núm. 15, del 3 de septiembre de 1985, y La Razón del 24 de agosto de 1985) y su «Carta a la Cámara Federal» tras conocerse la sentencia en diciembre de 1985 (en Clarín, 20/12/1985). 
ya que tras rehusarse a formular su descargo emitió luego por carta, con copia a la prensa, su parecer al tribunal por las sentencias. Pero a pesar de esas diferencias, tuvieron varios puntos en común. En primer lugar, todos se mostraron deseosos por hablar, incluso aquellos que dijeron poco. Fue notoria la ansiedad de los acusados aguardando su turno para tomar la palabra mientras escuchaban indiferentes las exposiciones de sus defensas. En segundo lugar, varias redes de sentido resultaron compartidas. El presente trabajo las revisa y analiza a partir de cuatro temas presentes en esos discursos: la «guerra antisubversiva», la idea de la «obediencia», la percepción de un «juicio injusto» y el rol de las Juntas.

\section{La guerra}

El tema expresado en la idea de una «guerra» como el marco simbólico y de acción en la década del setenta se comportó como el argumento central que edificó la estructura en las alocuciones de los excomandantes. Funcionó como premisa inicial, a la que se le otorgó un valor de verdad superior, y a partir de ella las restantes ideas fueron presentadas como enunciados derivados en aquellos discursos. Este argumento se apoyaba en el discurso de la «guerra antisubversiva», que se elaboró como una estrategia de interpretación colectiva -y luego se transformó en una memoria pública- para las fuerzas armadas a partir del golpe de marzo de 1976 (Canelo, 2008). ${ }^{7}$ Bajo un diagnóstico de situación en el que primaba la excepcionalidad de un enfrentamiento radical en clave bélica, pero que incorporaba también tonos apocalípticos y referidos al choque de culturas, el discurso de la «guerra antisubversiva» apuntaba a establecer un tipo de racionalidad que no era compatible con la práctica convencional de la guerra y enmarcaba la violencia desatada en esa excepcionalidad. Mediante ese aglomerado de sentidos, los excomandantes postularon que las características de aquella guerra no se adecuaban al lenguaje con el que quería analizarla el tribunal y, consecuentemente, que no tenía sentido establecer las precisiones que se les exigían respecto a los crímenes concretos.

Se postulaba, además, que la iniciativa en esa guerra, y consecuentemente los métodos adoptados, no habían sido decididos por las fuer-

\footnotetext{
${ }^{7}$ Sobre el proceso de construcción y cristalización de ese imaginario, y sus antecedentes rastreables, ver Canelo (2008).
} 
zas armadas, sino por la «subversión». Así, la génesis y la naturaleza de los crímenes -evadida en las presentaciones pero siempre implicada y dada por sabida- tenía en las voces de las Juntas a la «subversión» por su disparador causal:

Se ha procurado borrar de la conciencia pública que la defensa frente a la agresión subversiva fue legítima y que el triunfo estuvo signado por la justicia. [...] Una guerra provocada por fuerzas extremistas que, a lo largo de un decenio, ejecutaron 21.800 actos vandálicos (Videla, Carta a la Cámara Federal tras la sentencia, diciembre 1985). ${ }^{8}$

Mientras combatíamos, un eficacísimo sistema de persuasión comenzó a arrojar las sombras más siniestras sobre nuestra realidad hasta transformarla, al punto de convertir en agresores a los agredidos, en victimarios a las víctimas, en verdugos a los inocentes (Massera, $3 / 10 / 1985) .{ }^{9}$

[Fue] una guerra declarada y proclamada abiertamente por los jerarcas y pensadores marxistas (Viola, 12/10/1985). ${ }^{10}$

El país fue atacado por una subversión demencial, cuya finalidad era la toma del poder y el cambio de signo de la República y su procedimiento el terrorismo y la muerte indiscriminada (Graffigna, 16/10/ 1985). ${ }^{11}$

Con estas afirmaciones, intervenían en el debate público sobre las víctimas de la represión, afirmando que eran parte del universo «subversivo». Esa afirmación se construía como una contracara de la figura de la «víctima inocente» (que en el contexto cultural de la transición lidiaba socialmente con la estigmatización, heredada del marco dictatorial, de los eventuales compromisos políticos de las víctimas del terrorismo de estado), recurso que también había sido un medio para visibilizar los crímenes al ganar espacio en la cultura política a partir de su adopción en el Nunca Más, primero, y en las crónicas de los medios masivos sobre lo narrado en el Juicio a las Juntas, después (Crenzel, 2008). Sin embargo, los contenidos de la figura del «enemigo subversivo» no fueron discuti-

\footnotetext{
${ }^{8}$ Clarin, 20/12/1985.

${ }^{9}$ El Diario del Juicio, núm. 25, 12 de noviembre de 1985.

${ }^{10}$ El Diario del Juicio, núm. 30, 17 de diciembre de 1985.

${ }^{11}$ El Diario del Juicio, núm. 30, 17 de diciembre de 1985.
} 
dos en el juicio y dicha figura fue apropiada en ese contexto comunicativo de dos maneras: o bien se la trató como un elemento nominativo no ungido ideológicamente, o bien se la demonizó a través de una extrema simplificación, principalmente a partir de las voces militares:

Como profesión militar, personalmente no tengo ninguna duda, de que esto fue una guerra [...] Para ser sintético y emplear términos que ya están muy conocidos: la subversión buscaba la conquista del poder para imponer una ideología de izquierda totalmente ajena a las tradiciones, al sentir y al sistema de vida nacional, era algo distinto que se quería, se pretendía imponer para el país, ése era el objetivo político por el cual se buscaba el poder dentro de la Nación (Nicolaides, 26/04/1985). ${ }^{12}$

Sugiriendo la identidad de ese grupo en la relación con la guerrilla revolucionaria, pero sin precisar el límite ni las fronteras de ese enemigo, los excomandantes insinuaron que la participación en ese colectivo podía justificar el ejercicio de las violaciones a los derechos humanos (dadas las características excepcionales de la «guerra antisubversiva», y el hecho de que los «subversivos» fueron los «agresores»e impusieron así los términos del conflicto).

En el conjunto de enunciados propio del discurso de la «guerra antisubversiva», hubo un sentido complementario que cobró un peso particular en los discursos de los excomandantes, en comparación con las presentaciones de otros militares que declararon en las audiencias. Se trató de la idea de la «victoria» de las fuerzas armadas en esa lucha, idea que se mostraron deseosos en resaltar. A partir de esta última afirmación, los excomandantes construyeron sus demandas de reconocimiento y legitimidad, y expresaron, como se menciona más adelante, su indignación ante el hecho de que el Juicio tuviera lugar. El peso simbólico otorgado a esa «victoria» fue tan preponderante que Emilio Massera, incluso, tomó tiempo en su alocución para acusar a sus camaradas por haber abandonado la «guerra psicológica», retirada que -según entendía- derivó en aquel juicio que ponía en interdicción el logro obtenido en la «guerra de las armas».

En tanto que objeto discursivo central en las alocuciones, los excomandantes se mostraron en el juicio notoriamente más empeñados en

${ }^{12}$ El Diario del Juicio, núm. 1, 27/05/1985. 
reivindicar aquella idea la «guerra»-y sobre todo, la idea de la victoria en esa guerra- que de defender sus actos, y los de los subordinados, de la acusación delictiva.

\section{La obediencia}

Durante las audiencias del juicio, y a lo largo de los meses comprendidos entre abril y agosto de 1985, los testimonios de las víctimas y de sus familiares habían dado a conocer la serie infinita de abusos y vejámenes cometidos por los militares. En esas construcciones narrativas se había plasmado también una determinada caracterización de los autores de esos hechos. Marcadamente sustentadas en la experiencia individual, las narraciones dejaron patente que los secuestros, torturas y vejámenes que sufrieron fueron cometidos por sujetos determinados, cuyo rol particular se convertía en una pieza clave en los relatos que no se desdibujaba por el marco general del contexto represivo. Es decir, la identificación individual de los perpetradores directos tendía a dejar patente la idea de que existía una responsabilidad tanto criminal como moral también por parte de estos perpetradores, y no solo la que competía a los excomandantes que eran objeto del juicio.

En este punto, una idea, la de la obediencia, se mostró en los discursos de los excomandantes como una herramienta útil para dilución global de las responsabilidades penales. Por un lado, postularon que sus subalternos no tenían responsabilidad en los crímenes ya que esa responsabilidad (de existir) se articulaba y consustanciaba en el mando que había ordenado la acción puntual. Sin embargo, por otro lado, proponían que la misma idea eximía a los mandos por los posibles delitos cometidos por los subalternos en el curso del cumplimiento de las órdenes, ya que postulaban que esos delitos se podrían haber dado por los «excesos» o «errores» frente a órdenes presuntamente legítimas o por el abandono de la obediencia estricta. Esta última idea ya había sido ensayada en el «Documento Final de la Junta Militar» de abril de 1983. Ahora bien, jamás en el curso de las audiencias se brindó ejemplo alguno sobre los «errores» y «excesos» a partir de casos concretos, ni se definió qué tipo de actos podían ser considerados como tales.

De esta manera, en su sentido global, lo que estos discursos proponían era que si en esas acciones criminales no lograba probarse la obediencia propuesta en dichos discursos y en la cosmogonía militar como 
la clave de la responsabilidad mutua entre comandantes y comandadosno podrían sancionarse los delitos. Así, se postulaba en última instancia el ordenamiento de las relaciones sociales al interior de las fuerzas armadas como la clave hermenéutica a desencriptar si se deseaba comprender lo acontecido en los centros clandestinos y lo ocurrido a los desaparecidos.

Dado que la resistencia a hablar de los casos particulares contrastaba con el énfasis irrestricto en la celebración de la «guerra antisubversiva», ello permitía que los comandantes pudieran hacerse responsables de todo en general, y de nada en particular. Durante el Juicio, Nicolaides lo expresó del siguiente modo:

Nicolaides: Los comandantes se hicieron responsables — para ser amplio en la respuesta- de todo lo atinente a la lucha contra la subversión sobre la base de las órdenes y directivas que se dieron, creo, en la forma más completa posible. Entonces sobre las órdenes que se impartieron, ninguna duda, sí, sobre las directivas y órdenes que se impartieron.

Strassera (fiscal a cargo): [...] Pero mis preguntas son más concretas, ¿también se hacían responsables de la eventual comisión de tormentos por parte de los interrogadores? ¿También se hacían responsables de la eliminación física de personas? [...]

Nicolaides: Yo creo que es incriminatoria la pregunta, así que le pido no contestarla (Nicolaides, 26/04/1985). ${ }^{13}$

Ahora bien, en el orden simbólico, resulta significativo que en la serie de representaciones sobre la obediencia su valor se construía no solo a partir de la necesidad de impunidad (aunque acompañaba ese proceso), sino sobre todo a partir de representaciones más arraigadas que no tomaban ese requisito como eje.

En sus descargos, todos los excomandantes -con la excepción de Anaya, quien solo emitió un puñado de palabras- ${ }^{14}$ aludieron a ese problema. La desarticulación entre el mundo de la responsabilidad y el de los actos era posible porque, en primer lugar, la idea de la obediencia se expresaba no tanto como la relación de sujetos con acciones y decisiones determinadas o como una marca de inteligibilidad de los actos empren-

${ }^{13}$ El Diario del Juicio, núm.1, 27/05/1985.

${ }^{14}$ La presentación de Anaya (18/10/1985) fue la más breve del grupo: «Señores jueces, no tengo nada que agregar a lo ya expresado por mi defensa», acotó el marino. En El Diario del Juicio, núm. 30, del 17/12/1985. 
didos, sino como el producto de un lazo moral -asimétrico pero estableentre comandantes y comandados. En los discursos de los miembros de las Juntas, ese lazo se construía como una relación bilateral entre cada cuerpo armado y su comandante, circunscripta al período de duración de esas comandancias. Basado en el atributo de la lealtad, dicho vínculo moral concebía la responsabilidad como un correlato de la obediencia:

Estoy orgulloso de haber sido uno de sus comandantes en jefe y me honro con esos blasones [...] El mando exige subordinación y obediencia en el que cumple. Responsabilidad en el que ordena (Agosti, $7 / 10 / 1985) \cdot{ }^{15}$

Este imaginario explica, mejor que una mirada centrada solamente en su rol judicial, el énfasis depositado en el deseo de salvaguardar a los subordinados de tener que responder a la Justicia por su participación en los crímenes. Dicho deseo podía expresarse, además, bastante próximo a la idea de un sacrificio personal, tema que se hizo patente en las presentaciones de Videla, Massera, Lambruschini y Graffigna. La idea fue particularmente expresiva en el relato de Massera, el primero de la serie. El marino manifestó, con un acto de provocación, que era patente su predisposición a asumir las eventuales penas como un ritual de inmolación:

Si el tribunal necesita para eximir de responsabilidad a mis subordinados, a todos mis subordinados, que yo deba aceptar además que todas sus actuaciones fueron cumpliendo órdenes precisas que yo debiera haber impartido personalmente y en forma omnipresente, lo acepto. Yo y solo yo tengo derecho al banquillo de los acusados (Massera, $03 / 10 / 1985) .{ }^{16}$

Implícitamente, con ese enfoque, los miembros de las Juntas proponían que ese sacrificio también correspondía a los subalternos en favor de sus comandantes, ya que la responsabilidad y su contratara en la obediencia se concebían como una relación de lealtad recíproca. Y en esta medida, en forma similar a la que analizó Marcel Mauss (2009) con respecto a las propiedades simbólicas de los intercambios en sociedades tradicionales, el atributo de la lealtad se construía también con la forma

${ }^{15}$ El Diario del Juicio, núm. 27, 26/11/1985.
${ }^{16}$ El Diario del Juicio, núm. 25, 12/11/1985. 
de un intercambio afectivo y material de dones entre comandantes y comandados, en el que la ofrenda recíproca constituía un paisaje obligado.

$\mathrm{Al}$ intervenir y cuestionar, bajo nuevos parámetros, los términos de esa relación, la actuación de la Justicia reforzaba la indignación de los acusados frente al hecho de que el juicio tuviera lugar, cuestionamiento cuyo epicentro estuvo en el no reconocimiento que reclamaban para su actuación en la «guerra antisubversiva».

\section{Un juicio injusto}

A partir del vínculo orgánico postulado entre comandantes y comandados en la idea de obediencia, los acusados promovieron la idea de que el juicio -que los imputaba individualmente y sopesaba las responsabilidades personales- consistía en realidad en una persecución contra todas las fuerzas armadas y no solamente contra las Juntas.

[Este juicio] es una descomunal campaña publicitaria emprendida contra las Fuerzas Armadas (Videla, Solicitud para no comparecer a la audiencia de acusación, agosto 1985). ${ }^{17}$

Pero centralmente, la idea de un «juicio injusto», valoración que organizó las percepciones de los excomandantes sobre el proceso penal en curso, se edificó como la consecuencia de otra ya mencionada: la centralidad que otorgaban a la victoria en la guerra contra la subversión, y la forma en que, según entendían, el juicio la menoscababa. Es decir, en sus posiciones, el juicio era injusto no tanto por achacar los crímenes que vagamente asumían y concretamente negaban (los excomandantes intentaron correr los crímenes del foco en cuestión), sino por -en ese acto acusatorio- desconocer y retener los honores reclamados para aquella victoria.

Esa posición resultó un elemento común. Fue, sin embargo, objeto de diferencias en las estrategias de enunciación. Viola, por caso, solicitó al tribunal arbitrar las medidas necesarias para «seguir el desarrollo de la acusación con comodidad» ${ }^{18}$ y luego formuló el descargo más ex-

\footnotetext{
${ }^{17}$ La Razón, 24/08/1985.
}

18 Clarin, 31/08/1985. 
tenso de la serie tomando por objeto de embestida al fiscal. Otros, como Galtieri o Anaya, resolvieron delegar la estrategia de denuncia en sus defensores. Videla, en cambio, cuestionó explícitamente la legitimidad del tribunal desde un inicio: no designó un letrado defensor, más tarde transcurrió displicentemente el discurso del fiscal abocado a la lectura de literatura de cristiandad, y finalmente se rehusó a pronunciar su descargo ante los jueces, escogiendo en cambio para ello a la prensa tras la sentencia. O Massera, por ejemplo, extremó la estrategia con un discurso de arenga política, acusando al tribunal y al gobierno nacional de terroristas e identificándolos con la «subversión»:

¿Quién sería tan candoroso de pensar que se está buscando la verdad, cuando mis acusadores son aquellos a quienes vencimos en la guerra de las armas? Aquí estamos protagonizando todos algo que es casi una travesura histórica: los vencedores son acusados por los vencidos. Y yo me pregunto: ¿En qué bando estaban mis juzgadores? ¿Quiénes son o qué fueron los que tienen hoy mi vida en sus manos?; ‘eran terroristas?» (Massera, 3/10/1985). ${ }^{19}$

En todas esas acusaciones, notoriamente, el Poder Judicial y la clase política dirigente se construían como un único colectivo. Dos terceras partes de los acusados aludieron de distintos modos al gobierno de Alfonsín y su impulso al juzgamiento, y una proporción idéntica arremetió contra la actuación de la Justicia Federal. A partir de esa identificación, construían la sentencia de que el proceso penal se trataba de un «juicio político», dando a entender en ello la persecución facciosa e injusta. De ese modo, el evento penal fue considerado en un «deplorable espectáculo» (Videla y Lambruschini), ${ }^{20}$ un «fantástico juicio» (Massera) ${ }^{21}$ el «inédito proceso» (LamiDozo) ${ }^{22}$ o una infamia que sería condenada por el «juicio de la historia» (Viola). ${ }^{23}$

Los reproches al gobierno democrático presente funcionaron como extensión y continuidad de los formulados hacia la dirigencia política pasada y algunos aludieron a la responsabilidad de la clase política que,

\footnotetext{
${ }^{19}$ El Diario del Juicio, núm. 25, 12/11/1985.

${ }^{20}$ Videla, Carta a la Cámara Federal tras la sentencia, diciembre 1985; en Clarín, 20/12/

1985. Lambrushini, 14/10/1985; en El Diario del Juicio, núm. 30, 17/12/1985.

${ }^{21}$ Masera, 3/10/1985; en El Diario del Juicio, núm. 25, 12/11/1985.

${ }^{22}$ LamiDozo, 21/10/1985; en El Diario del Juicio, núm. 31, 24/12/1985.

${ }^{23}$ Viola, 12/10/1985; en El Diario del Juicio, núm. 30, 17/12/1985.
} 
según proponían, los «convocó». Las medidas represivas del gobierno peronista previas al golpe de estado fueron un lugar común en distintos acusados, y Viola anunció que durante su ciclo de «diálogo político» (González Bombal, 1991) no solo el «venerable y extraordinario líder» de la UCR Ricardo Balbín, sino también «quien es hoy un ministro del gabinete nacional» $\mathrm{y}$ «el hoy presidente de una cámara del Congreso Nacional» no habían formulado quejas por las violaciones a los derechos humanos. ${ }^{24}$ Videla denunció que la clase política pasada y presente carecía de «autoridad moral para arrojar la primera piedra», ya que fue ella la que promovió «el auge de un terrorismo salvaje». ${ }^{25}$ LamiDozo fue particularmente cínico. Sentenció que la clase política debía hacerse cargo de convocar a las fuerzas armadas «en su amparo», ya que los políticos saben que a los militares se los convocaba únicamente para matar. ${ }^{26}$ Así, Lami Dozo, después de negar su participación y la de su fuerza en los crímenes, los defendía y naturalizaba como un atributo esencial al colectivo militar local.

Según los acusados presagiaron, el «juicio injusto» podía malversar la victoria proclamada, y junto a esa pérdida se ponía en peligro la democracia, como parte de la afirmación de que la democracia era, según enfatizaban, un producto de aquella victoria contra los enemigos de la «patria», de la «forma de vida republicana»y de la «libertad». Videla y Massera anudaron además esas interpretaciones a la predicción de un apocalipsis político en el futuro cercano. En última instancia, proponían así a la Junta Militar como la institución protectora y conductora de la democracia en Argentina. Massera lo expresó del siguiente modo en el inicio de su alocución:

Si hubiéramos perdido no estaríamos acá -ni ustedes ni nosotros-, porque hace tiempo que los altos jueces de esta Cámara habrían sido sustituidos por turbulentos tribunales del pueblo y una Argentina feroz e irreconocible hubiera sustituido a la vieja Patria» (Massera, $03 / 10 / 1985) .{ }^{27}$

\footnotetext{
${ }^{24}$ Viola, 12/10/1985; en El Diario del Juicio, núm. 30, 17/12/1985.

${ }^{25}$ Videla, Carta a la Cámara Federal tras la sentencia, diciembre 1985; en Clarín, 20/12/ 1985 .

${ }^{26}$ LamiDozo, 21/10/1985; en El Diario del Juicio, núm. 31, 24/12/1985.

${ }^{27}$ El Diario del Juicio, núm. 25, 12/11/1985.
} 


\section{Juntas, pero separadas}

De modo paradojal, las responsabilidades políticas compartidas de los miembros de las Juntas -que eran recuperadas y puestas en primer plano por los excomandantes para hablar de una victoria colectiva en la que atribuían el triunfo, junto al triunfo militar, de la libertad y la democracia- iban a ser negadas, sin embargo, al rehusar la responsabilidad compartida de las Juntas en la conducción represiva.

Los excomandantes negaron sistemáticamente la responsabilidad compartida de la Junta Militar en la conducción del aparato represivo. En su alocución, Viola sentenció que entender la conducción solidaria de la Junta Militar en la «guerra antisubversiva» fue el primero de los «burdos errores cometidos por la Fiscalía». ${ }^{28}$ Esa recusación tenía dos antecedentes en democracia.

En el caso de los acusados, tuvo un precedente inmediato en el curso penal. Dos semanas antes del turno de los acusados, el fiscal Strassera elaboró su solicitud de penas basándose en la atribución de una responsabilidad planificada y compartida de los triunviros de la Junta Militar en cada una de sus conformaciones históricas. Prorratear en tres partes esa responsabilidad implicaba, obviamente, reducir las penas que a cada uno le habrían de corresponder. Esta estrategia de defensa legal tuvo un lugar destacado en las presentaciones de los abogados defensores. $^{29}$

Pero, en realidad, la afirmación sobre la autonomía de cada comandante había sido sostenida ya en las declaraciones indagatorias de los acusados ante el Consejo Supremo de las Fuerzas Armadas, durante 1984. En ese contexto, su uso se había asimilado, más que al deslinde de responsabilidades, a la voluntad de destacar logros individuales y de cada fuerza en particular en la «guerra antisubversiva» y así su orgullo y valor en función de esos logros:

El ejército, por razones específicas, por ser el componente terrestre, tenía la responsabilidad primaria en la conducción de las operacio-

\footnotetext{
${ }^{28}$ El Diario del Juicio, núm. 30, 17/12/1985.

${ }^{29}$ Para un análisis jurídico de la apuesta del fiscal, la negativa de Cámara Federal a darle lugar, y la lectura de la Corte Suprema en 1986 en sintonía con la Cámara para esa materia, véase Sancinetti (1988).
} 
nes, sin perjuicio de la asignación de zonas de seguridad que se habían hecho en beneficio de las otras fuerzas (Videla, 01/08/1984). ${ }^{30}$

Es decir, más allá de su posible eficacia judicial, la idea sobre la autonomía de cada arma se construía con voluntades de significación distintas al efecto penal. En el caso de los excomandantes, estuvo en buena medida transitada por la relación de reconocimiento recíproco postulada con sus comandados y la función dominante otorgada a la idea de la «victoria», propia y de sus hombres, en la «guerra antisubversiva».

Ahora bien, la afirmación que postulaba la independencia de cada fuerza no hacía mella, sin embargo, en el enunciado que sostenía la reivindicación de la «guerra antisubversiva» como un hecho colectivo.

La posición de los excomandantes de la Fuerza Aérea ilustra esa complejidad. Los brigadieres (y en especial Graffigna y LamiDozo) fueron los más predispuestos a rehusar la participación de sus hombres en el circuito represivo clandestino. Por cierto, ese argumento contrastó con la particular crueldad que los testimonios de sobrevivientes habían atribuido, durante las audiencias, a los perpetradores de aquella fuerza. En cambio, privilegiaron ensalzar la actuación de la Fuerza Aérea en otra «guerra», la de Malvinas, que presentaron como un correlato de la «guerra contra la subversión»:

[Fui] comandante en jefe de la Fuerza Aérea Argentina cuando la patria sufría desgarros y acechanzas de sus mayores enemigos, los de adentro y los de afuera, que querían arrancarle sus entrañas. [....] Al igual que sus hermanas la Fuerza Aérea tuvo que combatir, primero, a los apátridas y luego al enemigo extranjero. En esos combates se llenó de gloria y de mártires (Agosti, 07/10/1985). ${ }^{31}$

De ese modo, aunque refractaban la mayor cuantía de crímenes en la Armada y el Ejército y celebraban en cambio las acciones bélicas en los mares del sur, en sus discursos no desmentían la afirmación acerca de la existencia de otra guerra colectiva, la «antisubversiva», cuya victoria era un legado y un mérito también para la Fuerza Aérea a partir de la participación en ese colectivo, junto a sus «hermanas». Así, ponían de manifiesto que no estaban dispuestos a rehusar el imaginario de la «guerra

\footnotetext{
${ }^{30}$ Declaración indagatoria ante el Consejo Supremo de las Fuerzas Armadas; en El Diario del Juicio, Año I, Núm. 15, del 03/09/1985.

${ }^{31}$ El Diario del Juicio, núm. 27, 26/11/1985.
} 
antisubversiva», aun cuando atenuaban la responsabilidad individual (y de la propia fuerza) en los eventos, mostrando que el discurso de la «guerra antisubversiva» constituía, de distintas maneras, un núcleo de sentido transversal.

Una de las consecuencias significativas de esas posiciones consensuadas sobre la independencia de las fuerzas en el fuero represivo, afectaba a la interpretación política subyacente que así proponían sobre la práctica represiva. Lo interesante es que de ese modo tomaban distancia también de la interpretación social en ciernes, expresada en la idea de un «Juicio a las Juntas»y, sobre todo, del proyecto político transicional que propuso que era necesaria una condena social y moral a aquel régimen político, la dictadura, que tuvo ese órgano por institución principal. Al construir su responsabilidad en la red represiva en base a la relación de cada uno con la fuerza comandada y no por las decisiones políticas que asumieron al frente de la Junta Militar, los excomandantes desdibujaban enormemente el rol político de las Juntas Militares. Al diluir la responsabilidad del órgano político, la Junta, apostaban a recubrir de una siempre imposible- neutralidad técnica (la profesión militar) lo que era la pieza central de un programa político (la «derrota de la subversión»). Y de ese modo, procuraban imponer condiciones para la revisión de la apuesta política dictatorial.

\section{Conclusiones}

En sus presentaciones ante la Cámara Federal en 1985, los excomandantes de las Juntas Militares construyeron redes de sentido compartidas. Parcialmente, esas representaciones se encontraron mediadas por el contexto judicial, y consecuentemente el deseo de impunidad contribuye a explicar en forma complementaria sus estrategias argumentativas. Sin embargo, ese grupo de enunciados se mostró orientado, más que al desarrollo de una estrategia legal frente a los crímenes que se les imputaban, a la adopción del evento como un foro público donde podían establecer los ejes de su interpretación sobre el pasado inmediato y sobre las iniciativas de la transición política.

Por un lado, dispusieron en el eje de esas interpretaciones la memoria de una «guerra antisubversiva» y, sustantivamente, la idea de la «victoria» en ese enfrentamiento, que consideraban como el estamento central. A partir de ese enunciado, horadaron en la idea de la «obedien- 
cia» como el núcleo organizador de las acciones de las fuerzas armadas en los años de clandestinidad, pero rehusaron asumir o remitir responsabilidades penales concretas en los eslabones de esa cadena funcional. Con esas caracterizaciones, reforzaron a continuación, por un lado, la idea de la autonomía de cada arma en los crímenes cometidos, diluyendo las responsabilidades políticas que les competían en tanto miembros de la Junta Militar. Pero, por otro lado, recuperaron a la vez aquel ciclo político como un hecho colectivo, cuando clamaban se les reconozcan los laureles que competían por haber asegurado la «democracia» que el «juicio injusto» del presente hacía peligrar.

Con ese conjunto de enunciados, buscaban imponer cláusulas de interpretación para la continuación de los procesos penales por las violaciones a los derechos humanos cometidas en dictadura, pero, sobre todo, imponer claves de lectura políticas y memoriales para las representaciones colectivas sobre la violencia dictatorial.

\section{Referencias bibliográficas}

Acuña, C., y Smulovitz, C. (1995). Militares en la transición argentina: del gobierno a la subordinación constitucional. En C. Acuña et al.Juicio, castigos y memorias: derechos humanos y justicia en la politica argentina. Buenos Aires, Argentina: Nueva Visión.

Águila, G., Garaño, S., y Scatizza, P. (coords.) (2016). Represión estatal y violencia paraestatal en la historia reciente argentina: nuevos abordajes a 40 años del golpe de Estado. La Plata, Argentina: Universidad Nacional de La Plata, Facultad de Humanidades y Ciencias de la Educación.

Bacci, C., Capurro Robles, M., Oberti, A., y Skura, S. (2012). « $\Upsilon$ nadie quería saber»: Relatos sobre violencia contra las mujeres en el terrorismo de Estado en Argentina. Buenos Aires, Argentina: Memoria Abierta.

Badaró, M. (2009). Militares o ciudadanos. La formación de los oficiales del Ejército Argentino. Buenos Aires, Argentina: Prometeo.

Canelo, P. (2008). El Proceso en su laberinto: la interna militar de Videla a Bignone. Buenos Aires, Argentina: Prometeo.

Canelo, P. (2010). La responsabilidad y la convicción. Las 'autocríticas' delgeneralBalza y su impacto en la interna militarargentinaduran- 
te los añosnoventa. Militares e Política, (7), 100-116.

Canelo, P. (2016) La politica secreta de la última dictadura argentina (1976-1983). Buenos Aires, Argentina: Edhasa.

Cheresky, I. (1998). Régimen estatal de desaparición.Sociedad, (1213), 81-102.

Crenzel, E. (2008) La historia politica del Nunca Más: La memoria de las desapariciones en la Argentina. Buenos Aires, Argentina: Siglo XXI.

D'Antonio, D. (comp.) (2018). Violencia, espionaje y represión estatal. Seis estudios de caso sobre el pasado reciente argentino. Buenos Aires, Argentina : Imago Mundi.

Feld, C. (2001). La construcción del 'arrepentimiento': los ex represores en la televisión. Entrepasados, (20/21), 35-54.

Feld, C. (2016). El imposible «debate» entre víctimas y victimarios: notas sobre las declaraciones televisivas de Miguel Etchecolatz (1997). Rubrica Contemporánea, V, 77 - 101

Franco, M. (2012).Un enemigo para la Nación. Orden interno, violencia y «subversión», 1973-1976. Buenos Aires, Argentina: FCE.

Galante, D. (2017). 'La Constitucioìn y la prudencia': los tres niveles de responsabilidad para el juzgamiento de las violaciones a los derechos humanos en la transición argentina. Sociohistorica, (40), e036.

Glaser, B., y Strauss, A. (1999). Discovery of Grounded Theory: Strategies for Qualitative Research. New York, Estados Unidos: Routledge.

González Bombal, I. (1991).El diálogo politico: la transición que no fue, Documento CEDES/61. Buenos Aires, Argentina: CEDES.

Herschberg, E., y Agüero, F. (comps.) (2005). Memorias militares sobve la represión del Cono Sur. Madrid, España: Siglo XXI.

Novaro, M., y Palermo, V. (2003).La dictadura militar 1976-1983: del golpe de Estado a la restauración democrática. Buenos Aires, Argentina: Paidós.

Mauss, M. (2009).Ensayo sobre el don: forma y función del intercambio en las sociedades arcaicas. Buenos Aires, Argentina: Katz.

Quiroga, H. (2004). El tiempo del «Proceso»: conflictos y coincidencias entre politicos y militares: 1976-1983. Rosario, Argentina: Homo SapiensFundación Ross.

Robben, A. (1995). The politics of truth and emotion among victims and perpetrators of violence. En A. Robben, y C. Nordstrom 
(comps.), Fieldwork under Fire. Contemporary Studies of Violence and Survival, pp. 186-204. Berkeley/Londres, Estados Unidos/Inglaterra: University of California Press.

Robben, A. (1999). The fear of indifference: Combatants' anxieties about the political identity of civilians during Argentina's Dirty War. En K. Koonings, y D. Kruijt (eds.), Societies of Fear: The Legacy of the Civil War, Violence and Terror in Latin America pp. 125-140. Londres, Inglaterra: ZedBooks.

Salvi, V. (2012) De vencedores a victimas: memorias militares sobre el pasado reciente en la Argentina. Buenos Aires, Argentina: Biblos.

Salvi, V. (2015). Guerra, subversivos y muertos: un estudio sobre las declaraciones de militares en el primer año de democracia. En C. Feld, y M. Franco (Dirs.), Democracia Hora Cero: Actores, politicas $y$ debates en los inicios de la posdictadura. Buenos Aires, Argentina: FCE.

Salvi, V. (2016). «Entelequia», «enmascaramiento»y «disimulo». Las estrategias discursivas de Videla para hablar sobre los desaparecidos. Rubrica Contemporánea, V, 103-122.

Sancinetti, M. (1988).Derechos humanos en la Argentina post dictatorial. Buenos Aires, Argentina: Manuel Lerner. 